\title{
An Analysis on Current Situation of Management Talent in Hospital and
}

\section{its Cultivating Measures}

\author{
Zejuan Ren ${ }^{1,}$, Min Wang ${ }^{2}$ \\ ${ }^{12}$ Southwest Medical University, College of Humanities and Management, Luzhou, Sichuan, China, \\ 646000 \\ 1361056636@qq.com 1594047773@qq.com
}

Keywords: Hospitals' Management; Specialization on Management; Training on Professionals Abstract: With the integration of global economic, hospitals in China are faced with new opportunities and challenges. Hospitals' management level should be raised, in order to be suited to the environmental changes successfully. Based on the analysis of current situation on hospital management staff, this paper puts forward some recommendations as: put emphasis on the economic benefits of hospital management; establish standard training bases for hospital management; increase the number of professionals of hospital management and improve the quality of hospital management professionals and so on.

\section{Introduction}

AS the process of China joining in the WTO, the openness of China's medical market is increasing and international competition is becoming increasingly fierce. On the other hand, the domestic market is also facing a series of new situation: hospitals as controlled stocks by the investment holding groups, introduction into Hospital Brand and development of hospital collectivization, etc. Been wanted to survive and then develop in a huge crisis and challenge, China's hospitals have to improve their management level and the hospital management must be change from the experience into the scientific type. It is believed that the specialization of hospital management is imperative.

\section{An Analysis on Current Situation of Management Talent in Hospital}

\subsection{The Traditional Concept's Despising at Hospital Management's "Economic} Contribution". Management of the hospital is basically because of the outstanding in a field and was promoted to management positions; they are mostly clinical experts or technical backbone. It is considered by the traditional concept that the professional and technical personnel is the basis and the core of hospital, which is the direct guarantee for hospital's reputation, brand and economic benefits. While the management work is low in technical content and can be a very strong alternative by many people, which is not high on economic benefits.

However, the view above is biased. According to Katz Robert's study, managers have three skills (technical skills, interpersonal skills, and conceptual skills), the importance of which is not the same for different levels of managers. As for basic managers, technical skills are of the most importance; But technical skills are not so important for the higher management. The traditional concept of too much emphasis on medical professional technology and ignoring on management 
technology is not in conformity with the concept of modern management. The neglect of management economic value will inevitably lead to the neglect of management personnel training and the learning and training of management knowledge and skills.

2.2 Backward Mechanism in Management Selection. In the European and American countries, for example, in America, senior management of hospital, especially the President, vice President and head of various functional departments, are most not with a professional medical background. In general, with a law, economics, management and other professional background, most people have an MBA, MPA (master of public administration) or MHA (hospital management master's degree. $)^{[1]}$

This is consistent with a view of the West called "leadership and incompetence". The basic meaning of this view is that the leadership, especially senior leaders if have a too much understand of the professional, it is not conducive to economic efficiency, sometimes. For example, if a company's general manager is engaged in marketing background, he will be most sensitive to marketing, believing it the most important one, while ignoring other functions. Similarly, if the general manager is engaged in financial, production or R \& D and other background may also appear similar problems. In a word, Professionals are likely to focus in their own professional field has disrupting the order of the whole company, while the non-professionals make such a mistake rarely, so management (Leadership) becomes a specialized occupation.

That's why, the president of the hospital in the United States, can be a non-medical professional background, taking no stethoscopes, with no diagnosis and no treatment of patients. The situation is different in Japan. Only senior doctors are eligible to serve as president of the hospital, but also provides that the president must go through professional hospital management training. That's to say, the Dean should not only master the medical knowledge, but also have to master the management knowledge and master the operation of the hospital. ${ }^{[1]}$

The management of hospital in our country, most comes from of the medicine (nursing) professional positions, having not received a systematic management courses or training, management, basically relying on the experience, with a lack of management knowledge, management ideas and views. As a matter of fact, this belongs to the lowest level of leadership, known as the "elite leadership": With a strong performance for the elite traits, although in the leadership, they still engages in clinical professional work, who are still mainly responsible for professional services. Having a tough grasp on hospital professional operations and hospital economic operation together, which results in a low management efficiency and a limited $\mathrm{t}$ development, because of limited time as well as energy.

In contrast to the experience of developed countries, China's medical technology managers have been out of date. The improvement of hospital management level, the specialization construction of management team and the improvement of hospital operation efficiency are the urgent problems to be solved in hospital reform and development at the present stage.

\subsection{The Defects of the Training Mechanism of the Professional Personnel in Hospital} Management. Subject related to hospital management in China started late and the hospital management professional education system is still not perfect. At present, speciality of hospital management in Colleges and universities setted up in our country is not so popular. In addition to comprehensive universities, some medical colleges or universities set up undergraduate professionals as the social medicine and health management, Public Administration (hospital management direction) and so on. There is a master's degree in hospital management (MHA). But on the whole, professional hospital management graduates with a systematic study and training are not so many. Most of the hospital management are just get a short-term pre-job or on-the-job 
training or through personal experience to implement management. However, these training is not standardized having no uniform standard and often belongs to the spontaneous, disordered state while the hospital each acts in its own way. The effect of short-term training, of course, is far away from the formal system of professional education.

By contrast, developed countries in west put emphasis on cultivation and use of hospital management professional talents very early. The United States has carried out hospital management for a long time, and set health management education more than 50 years, already forming a quite mature, complete education system not only in the training goal, the curriculum structure but also about the education level and so on. As a result, it has the ability of train high quality hospital management professionals at all levels for hospitals. ${ }^{[1]}$

\section{The Countermeasures of Cultivating High-Quality Hospital Talents for Hospital Management}

3.1 Change Ideas and Pay Much More Attention to the Economic Benefits of Hospital Management. According to the classical economists, Marshall's view: Management, as a kind of acarce resource, can bring value to enterprises and other organizations. According to the research, in the case of the same structure and personnel, making change in management can improve the efficiency of enterprise at a rate of 50\%. ${ }^{[2]}$

Therefore, it is necessary to change the traditional concept of "medical technology is the direct guarantee of hospital benefits”. To make it clear that improving the management level of the hospital is the fundamental guarantee to enhance the economic efficiency of the hospital. Without first-class management, there is no first-class hospital benefits. As a kind of function activity, the management level of the hospital management can bring benefit to economic growth. Management is the base, means and way to improve the economic benefit and making economic benefit is the motive and the target of management.

3.2 Establish Standardized Management Personnel Training Base. It is suggested that special funding for the training base was provided by the central government and the provincial financial departments. Integrate the advantage resources in the province in order to establish the standardized unit medical and health management personnel training base, led by the ministry of health with the ministry of education, etc. trying to achieve the purpose of the hospital management personnel training standardization.

The training base is mainly for medical specialty of hospital management to accept the systematization and standardization of management training, aimed at improving the management level of hospital management.

Of course, the base construction is not a short duration of time; there are many key and difficult to overcome, such as a access to training base and the establishment of evaluation index, evaluation feedback mechanism for training students' ability of management , setting objectives, methods, time, content, programs and assessment methods, etc. for different professional, different management qualifications and management training program students.

3.3 Increase the Quantity of Hospital Management Speciality and Improve the Quality of Hospital Management Professionals. Given to systematic learning and training of professional hospital management graduates also is less, that can't meet the needs of hospitals at all levels, It is recommended that more qualified colleges and universities, especially the medical colleges and universities, set up the hospital management major and increase the supply of professional management talents. In the increase in the number of supply at the same time, quality improvement is more important, we must ensure that the quality of graduates.

At present, our country's health management education training object positioning is not 
accurate, talent training programs are relatively backward, the curriculum is not reasonable enough, and he training mode cannot meet the urgent requirements of the training of senior management personnel in the hospital. Therefore, we need to learn from the western countries mature health management education model, and make construction of the training mode of hospital management professionals in China based on China's national conditions, Including training objectives, curriculum, teaching content, training methods, etc. In particular, make full use of the advantage of the medical colleges affiliated hospital to improve the practical ability of graduates. Try to develop a hospital management undergraduate and postgraduate training program with Chinese characteristics in order to meet the needs of the development of the hospital and the urgent requirements of the reform of the medical and health system in china.

\subsection{In the Face of Different Levels of Management, Do a Implementation of Targeted Training}

3.4.1 As for the management of the basic level hospital, because of its high technical skills, it is best to select from the medical technical personnel. Then participate in the management of short-term or irregular training programs, with the main goal of mastering the basic knowledge and methods of management, and being familiar with the fundamentals of the hospital and the overall operating conditions.

3.4.2 As for middle hospital managers, with a background of management professional or medical professional both would be fine. If with a management background, it can refer to the clinical residency training method, doing a rotation, but the time can not be too short, as each functional department is about three or four months. It will Takes about 2 years to complete the whole process of rotation, to ensure a comprehensive understanding of the various aspects of the hospital business, learning the main body of the hospital management to grasp and deal with the details and in particular, all kinds of management processes in real-time processing skills, for the hospital management work to lay a solid foundation for business. ${ }^{[3]}$ If with a medical professional background, it can participate in the management of professional training programs.

3.4.3 As for the management of senior hospital, if without a management background, it can participate for a MHA or so. The main goal is to optimize the knowledge structure, absorb advanced management concepts and methods, grasp the medical quality standard of hospital performance management, meticulous management and other aspects of knowledge and the latest developments; being good at depth analysis of medicine, health care, hospital management system reform, and ultimately enhancing the ability of macro analysis, strategic decision-making.

\section{Conclusion}

China's health care reform is gradually deepening, and competition intensified with foreign hospitals and private hospitals; People's demand for medical services is increasing, which has put forward new requirements for the management of the hospital. That's why it is urgent to improve the professional level of hospital management personnel. Those who is not only familiar with the clinical medical professional knowledge, but also proficient in management science, mastering modern management theory and technology of modern hospital management talent is the inevitable choice of hospital, and it is also an important guarantee for the survival and development of hospital.

\section{Acknowledgements}

The project of Sichuan provincial hospital management and development center, 2015 Item number: SCYG2015-1-29

\section{References}

[1] Wang Baolin, Zhang Xin. Professionalization of the director is the key to the reform of public 
hospitals in the management of separation mode [J]. Jiangsu Healthcare Administration, Vol. 2009,20 (3): p7-8

[2] Rui Mingjie, Management - a modern view [M]. Shanghai: Shanghai people's publishing house, 2000:p403-404

[3] Zhao Lixia, Thoughts on the construction of hospital management personnel [J]. Journal of Shanxi Economic Management Institute, Vol. 2011， 19 (1): p23-24 